\title{
Case Study of Concrete Repairs on Jetty in Port Nolloth, Northern Cape
}

\author{
Malan Schrecker ${ }^{1}$, Duan Viljoen ${ }^{1}$, and Pierre van der Spuy ${ }^{2,3}$ \\ ${ }^{1}$ Aurecon South Africa (Pty) Ltd, Ports and Coastal Team, Cape Town, South Africa \\ ${ }^{2}$ Aurecon South Africa (Pty) Ltd, Transportation Unit, Cape Town, South Africa \\ ${ }^{3}$ Stellenbosch University, Civil Engineering Department, Stellenbosch, South Africa
}

\begin{abstract}
This paper describes the rehabilitation of the jetty in Port Nolloth, Northern Cape. The history of the jetty is not $100 \%$ certain, but it is believed that the previous wooden jetty was replaced by the current concrete structure towards the late 1940's. There were no as-built drawings of the jetty structure available. The jetty was in a deteriorated state and required a very thorough forensic investigation to determine the state of deterioration and to develop a design for the rehabilitation thereof. The forensic study, conducted by a specialist sub-contractor, included ferro-scanning (steel reinforcement number and spacing), core samples, non-destructive testing on the structure and visual inspections. From the investigation it was found that the concrete used for the jetty is generally of good quality (high strength, good compaction, and good aggregate distribution) and cover depths are in most locations in excess of 40 $\mathrm{mm}$. However, after 60 years of marine exposure the structure suffers from very high chloride contamination and severe rebar corrosion damage. Previous repairs were found to generally have failed to offer any noteworthy protection to the structure. Large cracks, spalled concrete and exposed corroded steel reinforcement were evidence of the chloride contamination. A structural analysis to verify the jetty capacity was also completed and it was found that it is imperative that the original cross-sectional area of the piles is restored. The methods proposed and employed to rehabilitate the jetty were patch repair (trowel applied concrete and sprayed concrete), sectional casting of concrete (with formwork), and replacement of reinforcement. The work commenced mid-2016 and was substantially completed end of 2017.
\end{abstract}

\section{Project description}

Transnet National Ports Authority (TNPA) appointed Aurecon to investigate the extent of deterioration of the jetty, improve the fender system and design a new coastal revetment to protect the shoreline. Aurecon was also appointed during the construction phase as design consultant, where Steffanutti Stocks Coastal was the contractor, Frontline was the HSE consultant and Sika the preferred material supplier.

During the design phase, TNPA requested that the useful life of the jetty should be extended by about 10 years - i.e. up to the year 2023.

The site is located approximately $150 \mathrm{~km}$ west of Springbok in the Northern Cape province of South Africa. The jetty is currently being used by De Beers as a Supply Chain Centre (SCC) to ship supplies to their offshore mining fleet. The SCC presently charters two supply vessels which operate from Port Nolloth. The history of the jetty very interesting. Some research revealed that the original timber jetty, from where copper ore was exported, was built around 1855. During the late 1940's a reinforced concrete deck-on-pile structure was constructed utilising the old timber structure as temporary false work. The jetty displayed extensive cracking and spall damage to beams, vertical faces, soffits and piles with corroded reinforcement visible in many places. Other areas where previous repairs were applied also showed signs of deterioration. Figure 1 shows an elevation of the jetty.

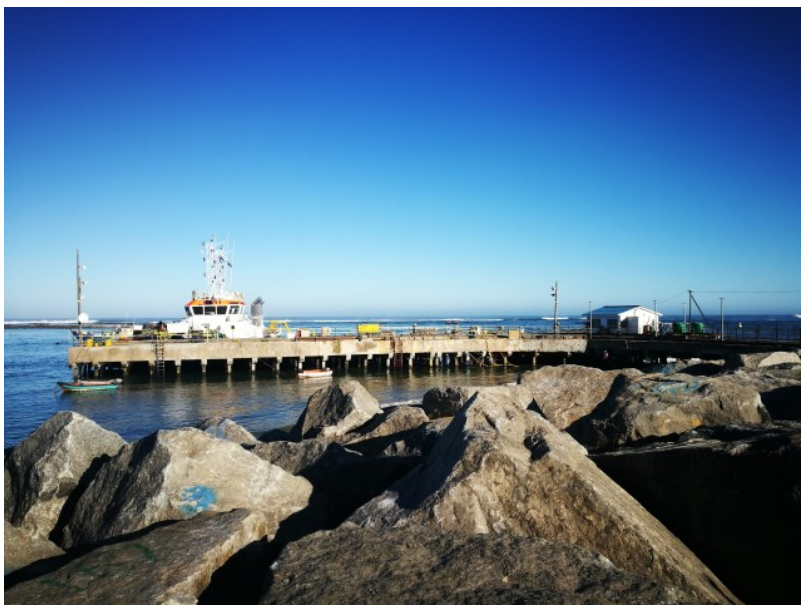

Figure 1: Elevation of the jetty in Port Nolloth

\section{Description of the structure}

The jetty structure consists of a deck on piles approach bridge and main jetty. The approach bridge is 
approximately $50 \mathrm{~m}$ long, perpendicular to the coastline, while the main jetty is approximately $66 \mathrm{~m}$ long, parallel to the coastline, with space for two of the supply vessels to moor. (refer Figure 2 below).

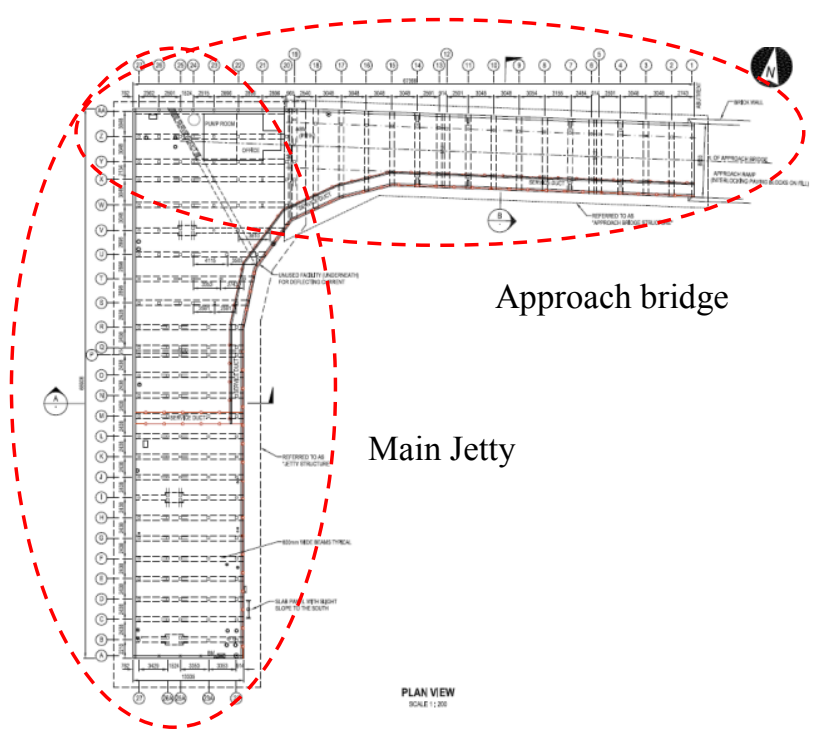

Figure 2: Jetty Layout

The approach bridge cross section is a $250 \mathrm{~mm}$ thick reinforced concrete slab over a $735 \mathrm{~mm}$ deep compacted sand fill, contained by a $180 \mathrm{~mm}$ concrete slab below, as shown in Figure 3. The total width, including a $1 \mathrm{~m}$ wide service duct, is approximately $8.8 \mathrm{~m}$. The approach bridge deck is supported by $600 \mathrm{~mm}$ deep and $500 \mathrm{~mm}$ wide beams at a spacing of approximately $3 \mathrm{~m}$ centre-tocentre. At most beams of the approach bridge there are only two vertical $300 \times 300 \mathrm{~mm}$ concrete piles with an additional two raking piles at four places along the approach bridge.

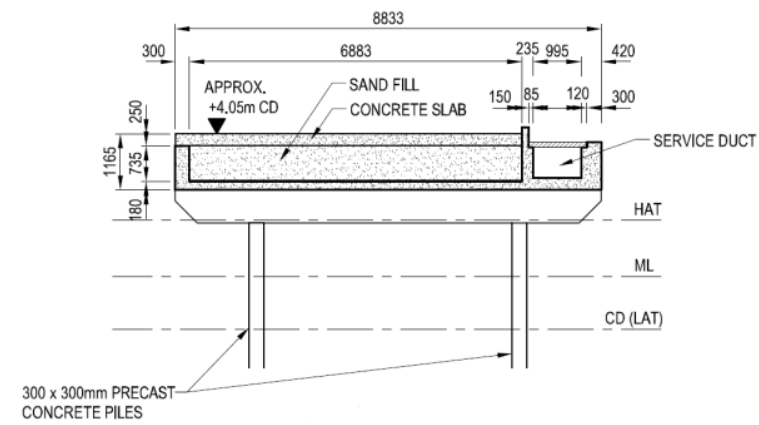

Figure 3: Approach bridge cross-section

The main jetty cross section is a $250 \mathrm{~mm}$ thick reinforced concrete slab over a $1035 \mathrm{~mm}$ deep compacted sand fill, contained by a $215 \mathrm{~mm}$ concrete slab below, as shown in Figure 4. The total width, including a $1.1 \mathrm{~m}$ wide service duct, is approximately $13.3 \mathrm{~m}$. The main jetty deck is supported by downstand/upstand beams, combined depth about $1050 \mathrm{~mm}$, with width $500 \mathrm{~mm}$ at a spacing of approximately $3 \mathrm{~m}$ centre-to-centre. At all beams of the main jetty there are three vertical and two raking 300x300mm concrete piles.

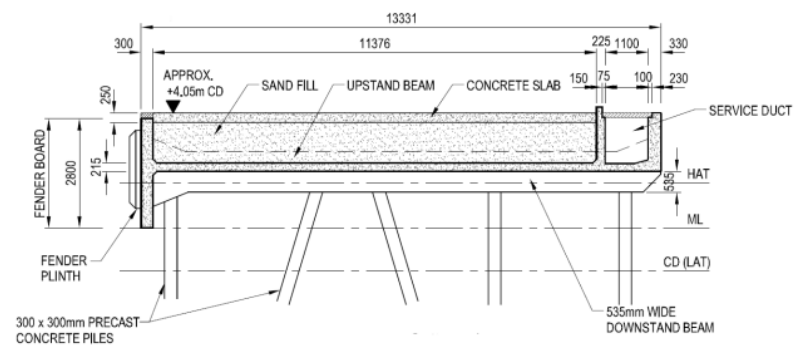

Figure 4: Main jetty cross-section

\section{Forensic Investigation Overview and Results}

A forensic investigation was conducted by subcontractors in July to August 2013 to determine the true extent of the corrosion and deterioration of the jetty structure. The output of the forensic investigation was used to determine the suitable repair procedures.

The investigation included the following methodologies:

- Ferro-scanning

- $\quad$ Steel Reinforcement number and spacing (confirmed by opening up of certain areas)

- Core Samples

- General concrete quality (compaction, voids, flaws, aggregate type, size and grading, etc.)

- $\quad$ Reinforcement properties (diameter, cover depth, signs of corrosion)

- Damage to the concrete (cracking, delamination)

- $\quad$ Signs of alkali silica reaction (ASR)

- Carbonation depth

- Chloride content

- Compressive strength

- Non-destructive testing on the structure

- Visual Inspections

- General condition

- Cracking (pattern, location, frequency, widths, cause)

- Reinforcement corrosion (cracking, rust stains, delamination, spalling)

- Performance of previously applied repairs (gunnite overlay, sacrificial anodes)

The investigation included condition assessment of various parts of the structure that are situated above the low tide water level, including the following:

- Piles

- $\quad$ Beams below the deck slab

- Deck slab soffit

- Top surface of the deck slab, including upstand beams

- Fender boards (on the west side of the jetty, inspected on west and east faces (east faces below the deck))

- $\quad$ South face of the jetty

- Previously repaired vertical faces of the jetty (north, south and east sides) 


\subsection{General concrete quality and contamination}

The concrete matrix was found to be well-compacted, well-graded and dense with virtually zero carbonation. There are, however, very high chloride levels present throughout virtually all structure elements.

\subsection{Coarse aggregate types}

The coarse aggregates used in the concrete appeared to be of various origins. The concrete in the deck superstructure mostly granite - being the natural aggregate of that region. Piles were found to contain greywacke ("Malmesbury shale") which is one of the common aggregates in the greater Cape Town area. It was concluded that the original contractor, Christiani \& Nielsen, which had its headquarters in Cape Town, may have fabricated the precast piles in Cape Town and then transported them to site. Greywacke are known to sometimes cause alkali silica reaction in concrete.

\subsection{Damage resulting from alkali silica reaction (ASR)}

The extent at which ASR has resulted in structural damage has not been investigated in the scope of this project. Examples of cores showing signs of ASR are shown in Figure 5.

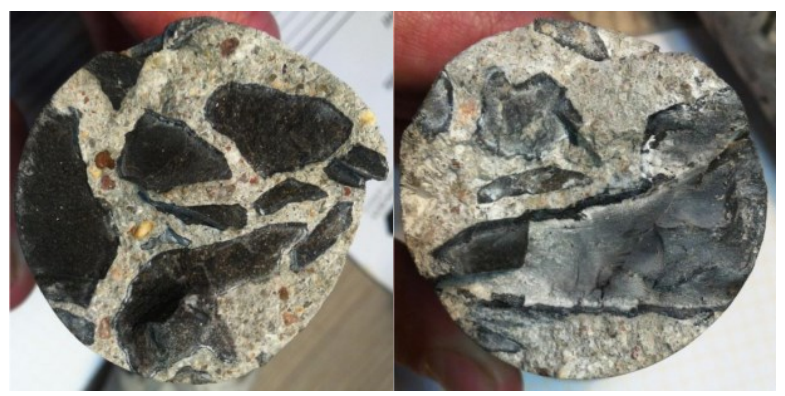

Figure 5: Cores from piles showing signs of ASR

However, during the site inspection no ASR-related cracking was observed on any part of the concrete surface. Considering the age of the structure, it is therefore unlikely that ASR will result in significant structural damage during the remaining service life of 10 years.

\subsection{Precast Piles}

The cover depths of the main (vertical) reinforcement varied significantly with values in the range of $30 \mathrm{~mm}$ to $55 \mathrm{~mm}$ and a mean cover depth of $45 \mathrm{~mm}$.

The measured piles showed a trend of relatively low rebar potential values with increasingly higher values towards the low water mark. The measurements suggested that the piles had a high to severe risk of corrosion (according to ASTM C876-91 (1999)). The measurements indicated that noteworthy reinforcement corrosion was occurring even in piles that showed no visible damage. This was expected and corresponds to the damage levels experienced (i.e. mostly cracking without delamination or spalling).

Concrete resistivity measured on the piles were low measured close to the water and higher just below the deck soffit. The values implied good and dense concrete, with values lower than $20 \mathrm{ohm}-\mathrm{m}$ indicating high moisture content in the tidal zone.

The piles were severely contaminated with chlorides well beyond the level of the steel.

Only very few piles showed significant rebar corrosion damage with signs of delamination. At the stage of deterioration during the investigation, significant structural consequences resulting from rebar corrosion (i.e. significant loss in load-bearing capacity) was not expected for the piles. Most of the piles (approximately 80\%) showed rebar-corrosion related cracking on one or more corners as seen in Figure 6 below. Approximately 40 no. piles were subjected to a delamination survey and in no case did the hammer sounding indicate delamination in the piles. However, some corner delamination was observed as seen in Figure 6 below.

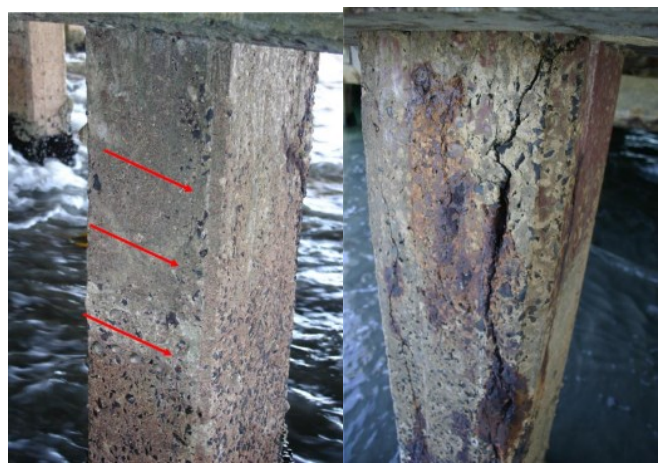

Figure 6: Pile that shows vertical cracking above the corner reinforcement (left) and pile showing delamination (right)

The piles suffered from ASR, which was believed to be in an uncritical, relatively early state.

\subsection{Deck slab soffit and beams}

The cover depths of the beams commonly ranged between 35 to $50 \mathrm{~mm}$ (horizontal reinforcement) and 30 to $45 \mathrm{~mm}$ (vertical reinforcement) and for the slab soffits it commonly ranged between 30 to $45 \mathrm{~mm}$ for both the main (i.e. longitudinal) and secondary (i.e. transverse) reinforcement.

The measurements suggested that the beams generally had a high to severe risk of corrosion (according to ASTM C876-91 (1999)), which corresponds to the damage patterns observed.

The beams and slabs were severely contaminated with very high chlorides well beyond the level of the steel reinforcement.

The deck of the bridge and jetty (slab soffits and beams) were in many locations in very bad condition with severe rebar corrosion damage (cracking, delamination, spalling, and loss of rebar cross-section) as seen in Figure 7 below. 


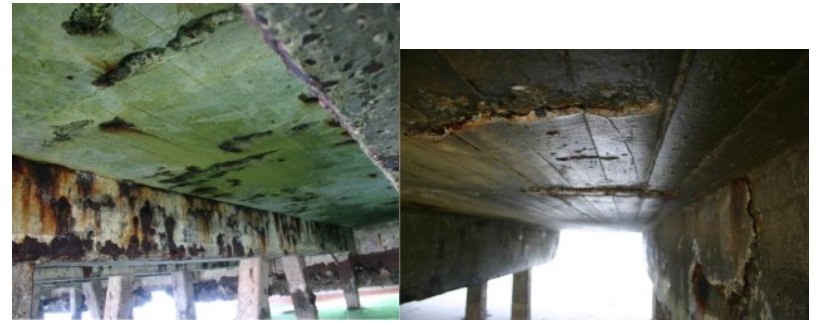

Figure 7: Severely damaged beam and deck soffit

The delamination survey revealed that many beams experienced high degrees of delamination. On the slab soffits, delamination was often occurring on more than $25 \%$ of the total area. These locations needed to be urgently repaired to avoid further degradation of the structural capacity. The beam ends (outside vertical and inclined faces) were consistently in particular poor condition and needed urgent repair as shown in Figure 8 below.

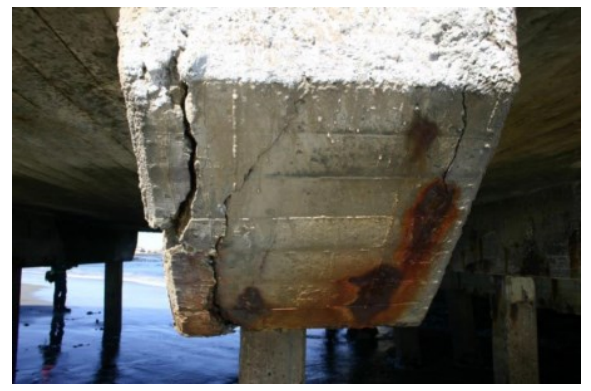

Figure 8: Typical failure of beam ends with severe corrosion damage

Most beams showed horizontal cracking at the bottom reinforcement, often along the entire length of the beam as shown in Figure 9 below.

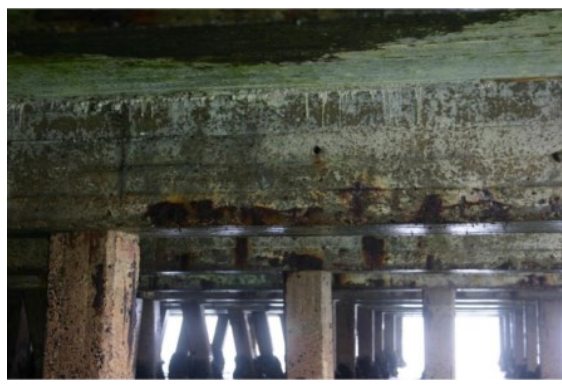

Figure 9: Typical horizontal cracking over horizontal rebars at the bottom of the beams

\subsection{Top of deck slab and upstand beams}

The cover depths of the upstand beams (and top slab surface) commonly ranged between 30 and $70 \mathrm{~mm}$ (45 and $65 \mathrm{~mm}$ on the slabs).

Resistivity values on the top of the slab and upstand beams indicated good, dense and relatively dry concrete in which reinforcement corrosion was not likely to occur at high rates.

The top of the slabs was severely contaminated with very high chloride levels well beyond the steel and showed some of the highest chloride concentrations in the structure.

The top surface of the slab and the upstand beams generally showed no signs of damage.

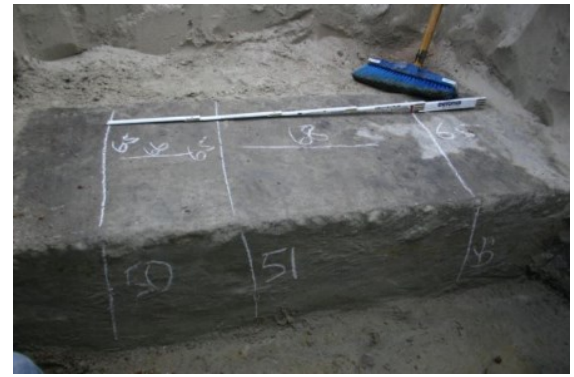

Figure 10: Surface of top of the slab and upstand beams showing no damage

Based on the 3 areas assessed, no repair of rebar corrosion damage needed to be carried out on top of the slabs or the upstand beams.

\subsection{Fender boards and south face of deck}

The cover depths of the western fender boards (on both west and east faces) and the south face commonly ranged between 40 and $60 \mathrm{~mm}$.

Resistivity values on the top of the fender boards and south face indicated good, dense and relatively dry concrete. At the bottom of the south face and fender board measurements indicated a higher water content (the bottom of the fender boards and south face are in direct water contact during high tide).

On the sea-facing sides, the fender boards were severely contaminated with very high chlorides well beyond the steel. Below the deck, lower chloride concentrations were measured. However, also below the deck, chloride concentrations were sufficient to initiate rebar corrosion.

The fender boards (west face) and south face were generally in an advanced state of rebar corrosion damage, with severe delamination, spalling, and loss of steel reinforcement cross section in many locations. Figure 11 shows an example of this.

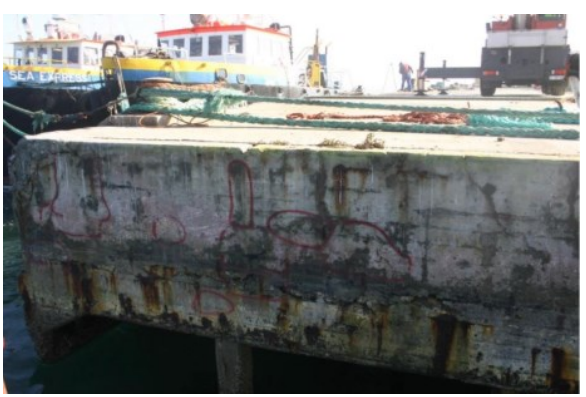

Figure 11: South face of deck, west side: delamination marked on the surface

The south-west corner of the fender boards and the north end were in particularly poor condition, with very advanced rebar corrosion damage shown in Figure 12. 


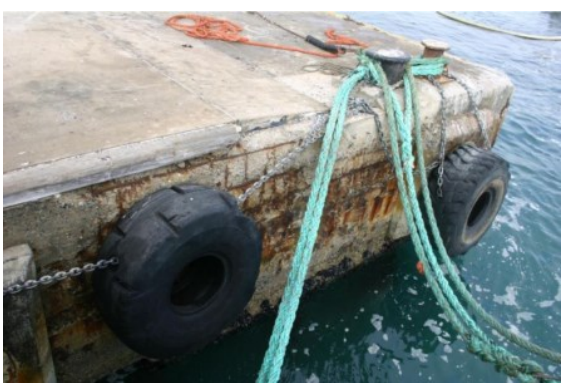

Figure 12: Fender boards, south-western corner. Severe rebar corrosion damage

A previously applied patch repair at the south-west corner of the jetty has failed completely.

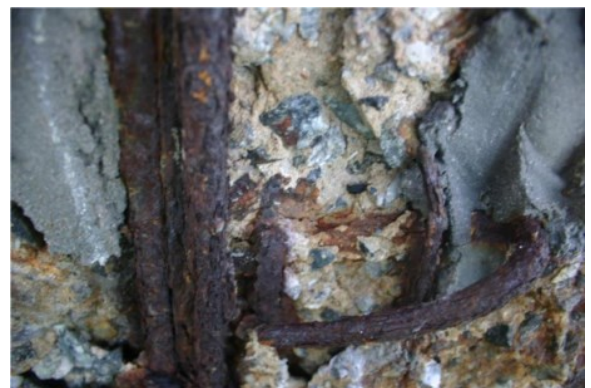

Figure 13: South-west corner of the jetty: failure of previous patch repair, severe steel corrosion

Non-visible delamination was identified in various locations on the south face, although most of the delaminated areas were easily visible. The west face of the fender board was cracked at the top (horizontal crack, approx. $200 \mathrm{~mm}$ below the top edge) along its entire length, which was in many locations combined with spalling, exposed rebar, and loss of rebar cross section as shown in Figure 14.

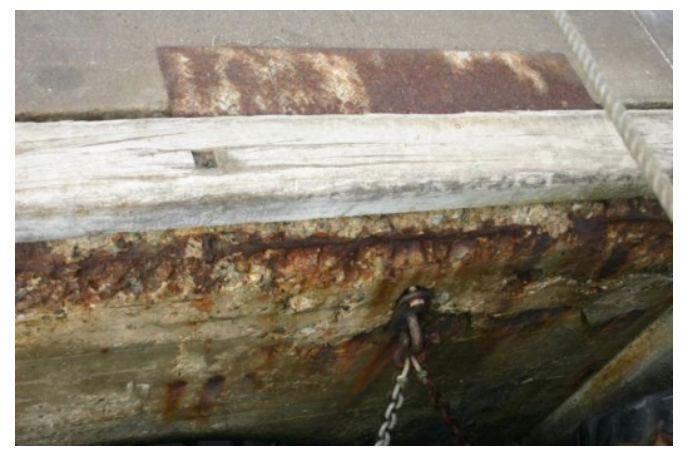

Figure 14: Fender board, west face: corroding horizontal steel bar on top of the fender board

The west face showed advanced abrasion from wave action along the bottom (approximately in the bottom $600 \mathrm{~mm})$, which however was not critical to the performance of the fender boards.

\subsection{Previously applied gunnite repair}

The previously applied gunnite was applied in varying thicknesses. It appears to have been applied on to the existing, smooth concrete surface without any attempt to roughen the concrete prior to gunniting as can be seen in Figure 15 below.

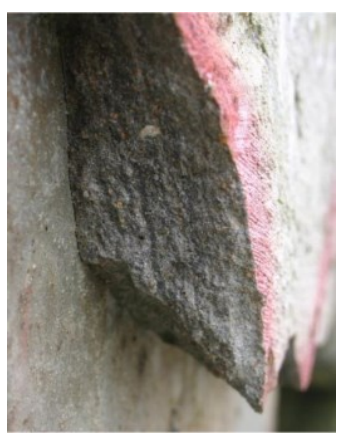

Figure 15: Close-up of gunnite repair showing smooth concrete surface

Some of the results of the delamination hammer test on the east face of the jetty are shown in Figure 16 below.

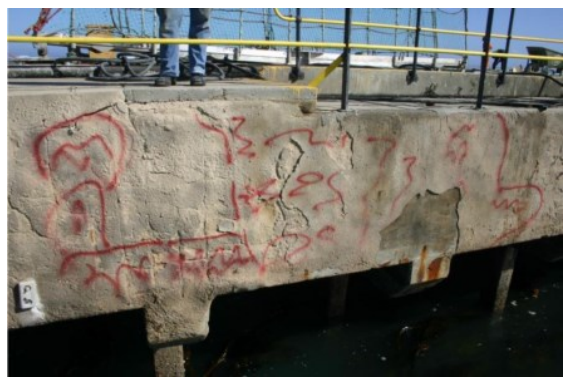

Figure 16: Results of hammer delamination survey on east face of jetty

A grey-coloured (probably cementitious) surface coating that had been brush-applied to the gunnite has failed completely and has largely peeled off. On the north face, the gunnite was cracked along the entire length, at a distance of about $250 \mathrm{~mm}$ below the top edge. Figure 17 shows what it typically looked like along the whole northern face.

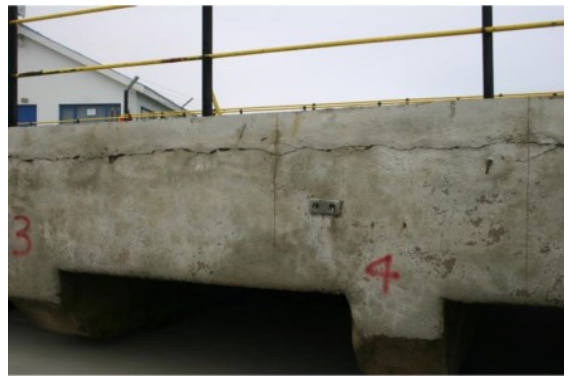

Figure 17: Horizontal cracking at cold joint of the northern face of the jetty

The gunnite showed shrinkage cracking in various locations and in some locations, the gunnite was showing cohesion failure or complete debonding. 


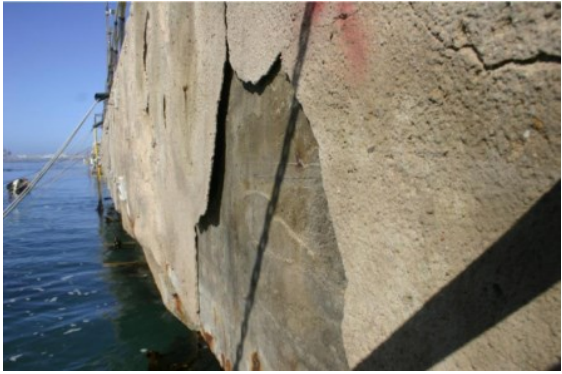

Figure 18: East face failing of gunnite repair debonding

The new steel that was placed into the gunnite as reinforcement was corroding in some locations as shown in Figure 19.

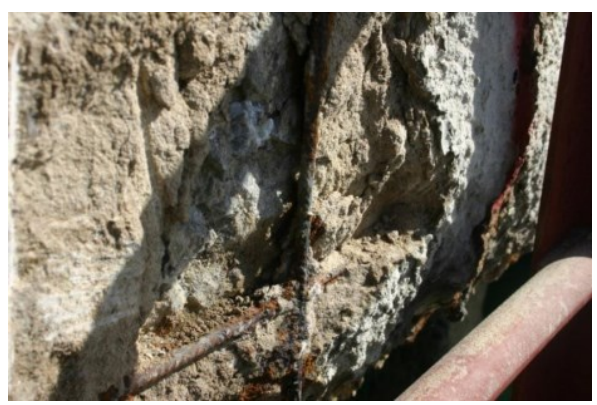

Figure 19: Corroded new rebar, added during gunnite repair inside delaminated gunnite layer

Except for the beam ends and the slab soffits, and except for the delaminated areas, the gunnite appeared in good condition with very few signs of corrosion-related cracking of the gunnite. Most of the bulk vertical faces of the gunnite appeared undamaged.

On the north and east faces (but not on the south face), the gunnite contained sacrificial anodes (as shown in Figure 20 below), which were usually connected to a steel mesh that was placed in the gunnite layer.

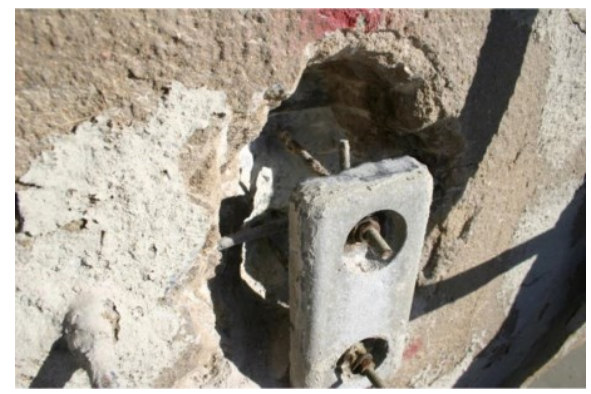

Figure 20: Sacrificial anode not connected to the reinforcement in the concrete

It became apparent that the anodes were only connected to the steel mesh in the gunnite but not to the reinforcement in the concrete. The anodes will not have protected the reinforcement from corrosion and were therefore ineffective.

Delamination was detected in various locations on areas ranging between less than $0.5 \mathrm{~m}^{2}$ and more than $2.0 \mathrm{~m}^{2}$. An estimated $20 \%$ of the gunnite has delaminated from the underlying concrete.

\section{Structural modelling}

A structural analysis had to be performed to assess the structure's ability to carry the imposed loads. The analysis was performed for the structure in its current state and repaired state. The following loads were taken into account:

-Self-weight of concrete members $(25 \mathrm{kN} / \mathrm{m} 3)$

-Weight of imbedded sand infill $(20 \mathrm{kN} / \mathrm{m} 3)$

-Mooring forces

-Berthing forces

- Crane outrigger load of $597 \mathrm{kN}$

- Fuel tanker on the platform (80 kN per axle)

- General live load on platform of $10 \mathrm{kPa}$

The most severe damage to the structure appeared to be the piles and these received special attention in the analysis. Other items analysed include the slabs and the beams. Figure 1 shows the structural analysis model performed in LUSAS.

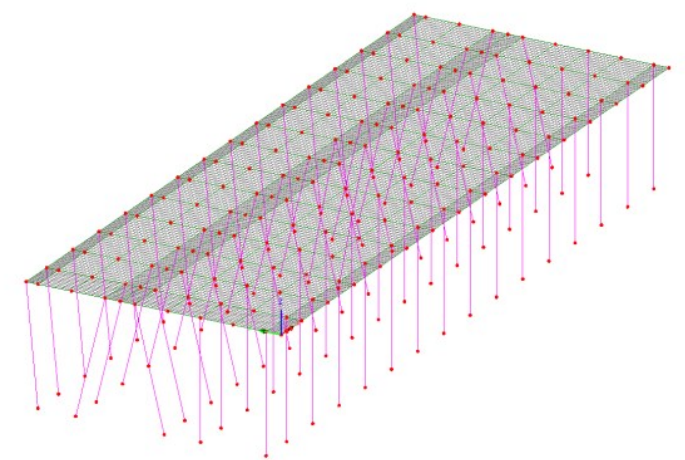

Figure 21: Structural analysis model.

\subsection{Analysis of piles}

The piles were constructed as $300 \times 300 \mathrm{~mm}$ square piles some of which deteriorated over time to $210 \times 210 \mathrm{~mm}$, significantly reducing the stiffness and structural capacity. Piles were reinforced with 4 R20 mild steel bars which was confirmed by breaking away surrounding concrete. In some areas the reinforcement was completely corroded. The piles were analysed as $210 \times 210 \mathrm{~mm}, 240 \times 240 \mathrm{~mm}$ and 300x300 mm.

The results of the analysis showed that failure is probable for $210 \times 210 \mathrm{~mm}$ and $240 \times 240 \mathrm{~mm}$ pile sections, especially where reinforcement is corroded. For $300 \times 300 \mathrm{~mm}$ the piles were found to be structurally sufficient which indicates that it was imperative to repair the piles to their original dimensions.

\subsection{Analysis of beams}

Scans showed that the $500 \mathrm{~mm}$ wide by $1000 \mathrm{~mm}$ deep beams are reinforced with $4 \times 220$ bars $\left(1257 \mathrm{~mm}^{2}\right)$ in the top and the bottom of the beams. Shear reinforcement was found to be R12 stirrups spaced at $200 \mathrm{~mm}$ giving an Asv/sv ration of 1.131 .

Analysis of the hogging moments resulted in a required reinforcement area of $1177 \mathrm{~mm}^{2}$ and a shear reinforcement ratio of 0.588 . Analysis of sagging moments resulted in a required reinforcement area of 
$800 \mathrm{~mm}^{2}$ and a shear reinforcement ratio of 0.424 . It was therefore concluded that the provided reinforcement is sufficient.

\subsection{Analysis of slabs}

Core drilling through the slab showed an average depth of $215 \mathrm{~mm}$ with R16 bars in both directions top and bottom. This was confirmed with ferro-scanning.

By allowing for moment redistribution in the slab it was shown that the required amount of reinforcement for hogging moments is $1275 \mathrm{~mm}^{2}$ which is less than the $1340 \mathrm{~mm}^{2}$ provided.

\subsection{Conclusion on deck analysis}

The piles in the structure were shown to be the critical elements. The analysis showed that the piles are very sensitive to length and state of disrepair. For the piles to function for another 10 years it was imperative to repair them to their original state.

The beams and the slabs were generally in good condition and the analysis showed no problems in carrying the applied loads provided that durability is restored to the structure.

\section{Repair Strategy}

Based on the forensic investigation it was determined that should the life of the jetty structure be extended further than an additional 10 years from August 2013, major rehabilitation works, such as replacement of structural elements, will be required. It was therefore decided with the client that the design life of the repair works need not extend beyond 10 years from August 2013.

The following repair strategy was proposed for all structural elements (piles, beams, deck slab soffits, fender board, and south face):

1. Identify the structural elements that are badly delaminated and/or cracked and that need repair. This was to be done visually and by hammer sounding survey.

2. Identify the structural elements that are mildly delaminated and/or cracked and that do not need immediate repair. Record their present state of corrosion by a description of damage, good photographs and position in the structure. These elements are to be re-assessed during the next condition investigation.

3. For structural elements that need immediate repair (as per (1) above), proceed with removal of concrete at least $50 \mathrm{~mm}$ past the damaged concrete or $25 \mathrm{~mm}$ past the reinforcement and then prepare the substrate (cleaning and roughing the surface).

4. Replace the reinforcement steel that is badly corroded and sufficiently lap with the good existing reinforcement, or install coupler where no space is available for lapping. Apply two layers of SikaTop
Armatec-110 EpoCem or equal approved to all the reinforcement within the patch.

5. Depending on the situation, choose the method of applying repair mortar: either

a. sprayed concrete, or

b. trowel applied mortar, which, in turn, may be either

i. Conventional polymer modified mortar, or

ii. Rapid setting mortar.

c. concrete casting in conjunction with formwork

6. Install sacrificial anodes (e.g. the Sika FerroShield Patch system, or equal approved) at approximate spacings of $700 \mathrm{~mm}$.

7. Proceed with repair of concrete and complete the treatment in accordance with each method's respective methodology (sprayed concrete, trowel applied mortar or concrete casting in conjunction with formwork).

8. Once the repair mortar/concrete has set, apply two coats of water repellent surface coating (e.g. Sikagard-706 Thixo Silane Cream at a rate of $0.3 \mathrm{~kg} / \mathrm{m} 2(=0.331 / \mathrm{m} 2)$, - or equal approved) to the repaired area.

\section{Implementation of repair methodologies}

Implementation of the repair procedures took place between August 2016 and December 2017.

\subsection{Challenges during construction}

The Contractor experienced several challenges with implementing the repairs, some of them being summarized below.

\section{Tidal range, wave exposure and currents}

The tidal variation is approximately $2.2 \mathrm{~m}$, with mean high-water springs (MHWS) level to the soffit of the beams (see Figure 22 below), making working underneath the deck impossible.

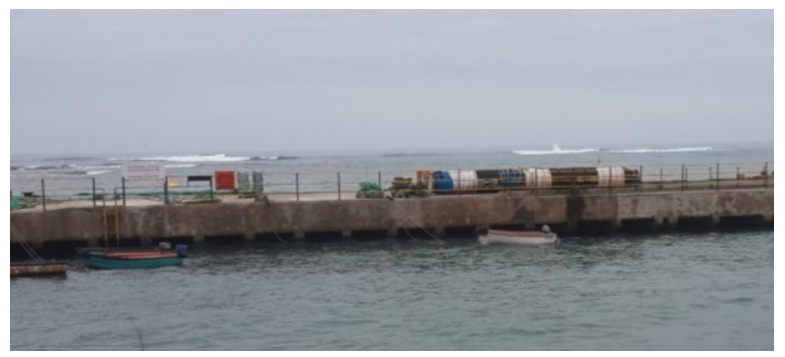

Figure 22: High-water at the jetty up to the soffit of the beams

This meant that work could only take place between mean sea level (MSL) and low-water, effectively giving the Contractor only a 6-hour window a day to complete works beneath the deck. This significantly affected the total duration of implementation. 
There is a very strong current flowing from South to North in the bay area on the land side of the offshore reef that at times can be so strong that works underneath the jetty cannot be safely completed.

The site is only protected by an offshore reef, which meant that at times the waves coming past the reef are too big to safely work underneath the jetty.

All the above factors significantly affected the programme.

\section{Remoteness of the town}

The closest relatively large town to Port Nolloth is Springbok, which is $140 \mathrm{~km}$ by road away. This meant that delivery costs and time were significantly higher, affecting the overall contract cost and programme.

\section{Access beneath the jetty}

Due to the impracticality to prop off the seabed, the constant current, tidal and wave action, the Contractor had to develop an innovative way of providing access to the workers implementing the repair works. The access system used consisted of expanded metal platform units supported on steel joists, supported on steel friction clamps attached to the existing precast piles.

\section{Total extent of repair works unknown at start of contract}

The extent of the repair works could only be estimated by the designer prior to the construction tender phase, based on the forensic investigation results. The forensic investigation could not cover every single element in the structure due to the cost and time something like that would have required. Therefore, the Contractor only found out the true amount of concrete and steel to be prepared once they were on site.

This was also a risk to the Client as the total contract value, along with duration, could increase significantly.

\subsection{Removal of damaged concrete and preparation of substrate}

The damaged concrete was removed with lightweight pneumatic concrete breakers and angle grinders.

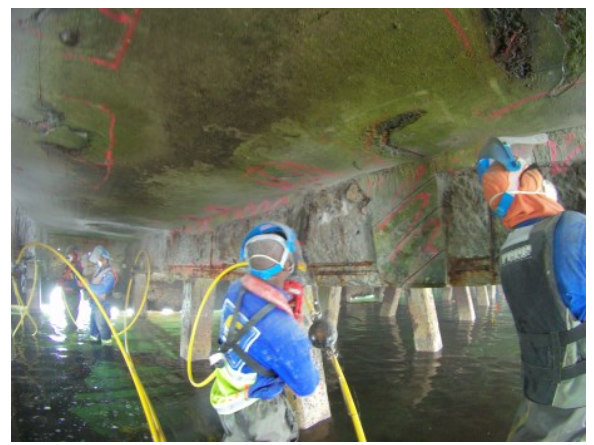

Figure 23: Worker removing concrete with pneumatic concrete breaker
Clean, potable water was used to clean the substrate.

\subsection{Replacement of reinforcement steel}

The reinforcement steel was replaced like-for-like, i.e. the same diameter as the existing steel that was corroded. This replaced steel, along with the existing steel within the patch, was coated with two layers of SikaTop Armatec-110 EpoCem. Where full lap-lengths for rebar could not be achieved, reinforcing bar couplers were employed.

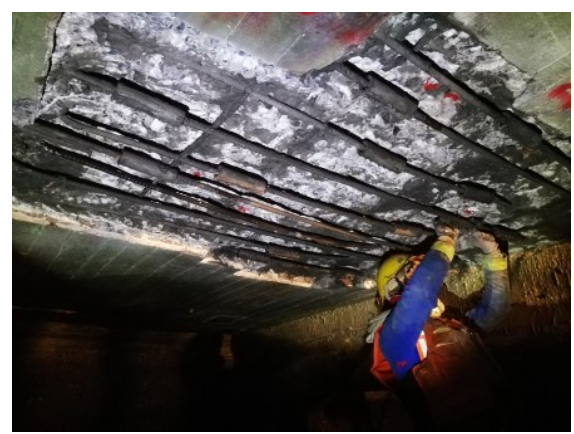

Figure 24: Reinforcement touched up with protective coating

\subsection{Sprayed concrete method}

At the start of the contract, the Contractor had a concern with how the sprayed concrete will be applied underneath the jetty due to space restrictions - i.e. it will be difficult to vertically apply sprayed concrete to the soffits of the deck as there will not be space to fit the nozzle of the spray gun. After discussions between the Contractor, the Designer and the Client, this method was discarded

\subsection{Trowel applied mortar method}

This method was mostly applied to the deck- and beam soffits and beam sides as well as to patch the top area where the concrete casting stopped. Sika MonoTop-615 $\mathrm{HB}$ and in certain cases SikaQuick-2500 was applied.

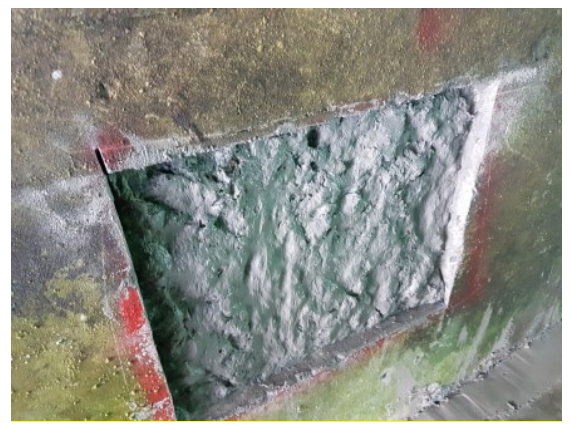

Figure 25: Mid-way through a patch using the trowel applied mortar method 


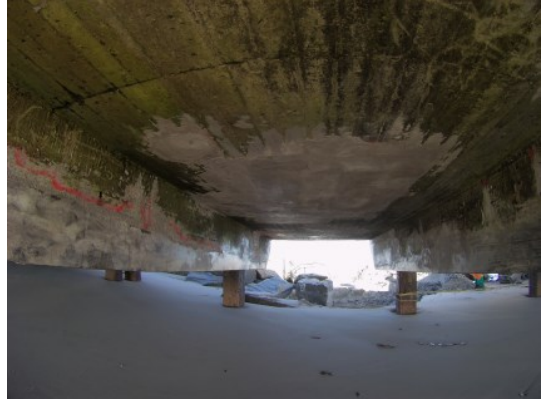

Figure 26: Completed trowel applied mortar patch repair on soffit of deck of approach bridge

\subsection{Casting of concrete in conjunction with formwork}

To increase the speed at which repairs are completed, the Contractor requested whether they can proceed with repairing elements with vertical faces (like beams, vertical faces, piles) by casting concrete in conjunction with formwork. This request was approved and a procedure developed to which they had to conform. SikaGrout 212 was applied with granite aggregate.

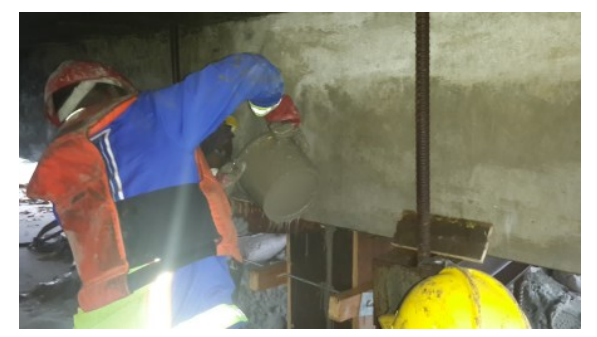

Figure 27: Application of casting concrete in conjunction with formwork of a pile

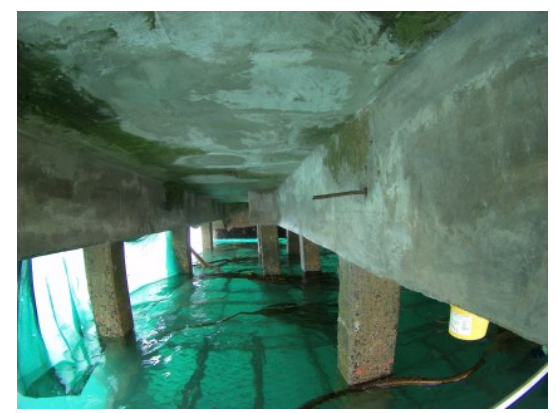

Figure 28: Finished product after using casting of concrete methodology

\subsection{Application of water repellent surface coating}

Two coatings of Sikagard-706 Thixo Silane Cream were applied to the whole surface area of each repair.

\section{Conclusion}

The jetty at Port Nolloth presented several defects including large cracks, spalled concrete and exposed corroded steel. The prime cause of these defects - as

mostly is the case for concrete structures in a marine environment - is chloride contamination. This paper presented the findings of a forensic investigation conducted by concrete specialists, a structural modelling analysis to verify the structural capacity of the jetty and the repair methodology proposed by the designer. It is believed that the service life of the jetty structure will successfully be extended. Regular monitoring and occasional maintenance will, however, be required.

\section{Project participating parties}

Owner and Client

Consulting Engineer

Specialist subcontractor/concrete consultant

Contractor Repair Materials Supplier
Transnet National Ports Authority (Pty) Ltd Aurecon South Africa (Pty) Ltd Prof. Dr. Hans Beushausen and team of post graduate students (BKM on-site coring contractor) Stefanutti Stocks (Pty) Ltd Sika South Africa (Pty) Ltd 